\title{
Quantitative trait loci for fertility traits in Finnish Ayrshire cattle
}

\author{
Nina F. SchUlman ${ }^{1 *}$, Goutam SAHANA ${ }^{2}$, Mogens S. LUND ${ }^{2}$, \\ Sirja M. VIITALA ${ }^{1}$, Johanna H. VILKKI ${ }^{1}$ \\ ${ }^{1}$ MTT Agrifood Research Finland, Biotechnology and Food Research, \\ 31600 Jokioinen, Finland \\ ${ }^{2}$ Department of Genetics and Biotechnology, Faculty of Agricultural Science, \\ Aarhus University, Research Centre Foulum, 8830 Tjele, Denmark
}

(Received 17 May 2007; accepted 25 September 2007)

\begin{abstract}
A whole genome scan was carried out to detect quantitative trait loci (QTL) for fertility traits in Finnish Ayrshire cattle. The mapping population consisted of 12 bulls and 493 sons. Estimated breeding values for days open, fertility treatments, maternal calf mortality and paternal non-return rate were used as phenotypic data. In a granddaughter design, 171 markers were typed on all 29 bovine autosomes. Associations between markers and traits were analysed by multiple marker regression. Multi-trait analyses were carried out with a variance component based approach for the chromosomes and trait combinations, which were observed significant in the regression method. Twenty-two chromosome-wise significant QTL were detected. Several of the detected QTL areas were overlapping with milk production QTL previously identified in the same population. Multi-trait QTL analyses were carried out to test if these effects were due to a pleiotropic QTL affecting fertility and milk yield traits or to linked QTL causing the effects. This distinction could only be made with confidence on BTA1 where a QTL affecting milk yield is linked to a pleiotropic QTL affecting days open and fertility treatments.
\end{abstract}

QTL / fertility / dairy cow

\section{INTRODUCTION}

High fertility in cows is economically important for dairy farmers. Low fertility leads to higher replacement costs, veterinary costs, labour costs and costs due to reduced milk production. The proportion of fertility treatments represents $21 \%$ [36] of all the veterinary treatments in Finland. Also, 20\% of the involuntary culling cases in Finland are due to fertility disorders (Rautala, personal communication, 2004).

*Corresponding author: nina.schulman@mtt.fi

Article published by EDP Sciences and available at http://www.gse-journal.org or http://dx.doi.org/10.1051/gse:2007044 
Fertility traits have a low heritability and are often difficult to measure [31]. Genetic progress by traditional breeding can therefore be slow and the negative correlations with production traits are of special concern [34]. Pösö and Mäntysaari [34] have reported that a genetic improvement of $500 \mathrm{~kg}$ milk yield would increase cases of ovulatory disorders by $1.7 \%$-units and days open by 4.2 days. These are traits for which marker-assisted selection could increase genetic progress compared to traditional breeding schemes [25,38].

Attempts have been made to map loci affecting fertility. QTL have been detected for ovulation rate [4], twinning [26], days open [39], non-return rate and stillbirth [24], fertility treatments [15], and pregnancy rate [2]. In Finland, mapping fertility traits is feasible because there is a good health data recording system with a database maintained by the Agricultural Data Processing Centre Ltd.

Several studies have found unfavourable associations between milk production traits and fertility traits $[23,34,37]$. Cows with high milk yield records tend to have poorer fertility performances than cows with moderate or low milk production. Selection for high milk yield has led to longer intervals between calving and the following pregnancy and an increase in fertility disorders. In order to use marker information to select for better fertility without compromising improvement in milk production, more knowledge on the chromosomal regions affecting both milk and fertility traits and the underlying genes is needed. Milk production traits and fertility traits are correlated genetically. This genetic correlation may be due to pleiotropic QTL affecting both traits simultaneously and/or to linked QTL each affecting one trait. For effective marker-assisted selection, it is necessary to distinguish between a pleiotropic QTL and a linked QTL to avoid undesirable correlated responses. The standard way of deciding how many QTL (marginal effects) and their interaction effects should appear in the final model relies on comparing several models, e.g. single-trait analysis with one or multiple QTL models followed by multitrait analysis with pleiotropic or linked QTL models. There are two limitations of this approach: first, it allows the comparison of nested models only; second, it is not clear how to adjust the significance threshold for each consecutive test [5]. Akaike information criterion (AIC) [1] or Schwarz Bayesian information criterion (BIC) [41] are two criteria that do not require that the compared models be nested and they have often been employed to choose marker covariates for multiple QTL mapping $[16,17]$ or to directly estimate QTL number e.g. [3, 5, 7, 30, 42]. Piepho and Gauch [33] have investigated model selection criteria via simulation. Their results suggest that out of the considered 
criteria $\mathrm{BIC}$ has the best properties and can be used for the estimation of the number of QTL with main effects.

The objectives of this study were (i) to use the Finnish granddaughter design data to map QTL for fertility traits (days open, fertility treatments, paternal non-return rate, and calf mortality in the Finnish Ayrshire population); (ii) to distinguish between pleiotropy and linked QTL when a region is affecting more than one fertility trait or at least one fertility trait and milk trait identified previously by Viitala et al. [46].

\section{MATERIAL AND METHODS}

\subsection{Traits and population}

Days open (DO) is calculated as the number of days from calving to the following pregnancy. Fertility treatments (FT) include information about fertility treatments done by a veterinarian within 150 days after calving and information about culling due to fertility problems. Non-return rate (NRR) indicates the ability of a bull to make cows pregnant. Its evaluation is based on the insemination of the bull's semen to a random set of cows and in this study, is measured as the non-return rate within 60 days from insemination with the first 500 inseminations of a bull included in the data. Calf mortality (CM) is measured here as a trait of the sire of the cow. It indicates the mortality at birth of the offspring of the daughters. The response variables used in QTL mapping were breeding values obtained from the Finnish Animal Breeding Association mainly from the evaluation carried out in autumn 2000. For NRR, the breeding values from the evaluation carried out in spring 1996 were used because there was not enough data for the six oldest grandsires in the year 2000 evaluation for NRR.

Breeding values for DO were estimated using a repeatability animal model and for FT a repeatability sire model. Records from the first three lactations were used. All bulls in the mapping population had daughter records from all three lactations. For CM a sire-grandsire model was used. CM and FT were recorded as binary traits. The heritability estimates used for calculating the breeding values were 0.05 for DO, 0.01 for FT, 0.03 for $\mathrm{CM}$, and 0.03 for NRR.

The milk yield traits used for pleiotropic and linked QTL analyses were the following: milk yield $1^{\text {st }}$ lactation (MY), protein yield $1^{\text {st }}$ lactation (PY), fat yield $1^{\text {st }}$ lactation (FY). Daughter yield deviations (DYD) originated from a test day animal model.

A granddaughter design was used for QTL mapping. Twelve Finnish Ayrshire half-sib families were genotyped. Only eleven of them could be used 
for the analysis of CM because the smallest family did not have enough sons with daughter records for this trait. The number of genotyped sons per sire ranged from 21 to 82 with an average of 41 sons. The total number of sons in the population was 493 . The average number of daughter records per bull was 496 for DO, 468 for FT, and 841 for CM.

\subsection{Markers and genotypes}

Markers were genotyped on all 29 bovine autosomes. All available sons of the chosen bull sires were typed. A total of 169 microsatellites and two candidate gene SNP were used. Out of these, 21 microsatellites were new compared to those reported in previous studies with the Finnish granddaughter design $[40,46]$. Thus, eleven linkage maps were recalculated. The linkage maps are available at http://www.mtt.fi/julkaisut/cattleqtl. The number of markers per chromosome varied from 2 to 14 . The average spacing between markers was $19 \mathrm{cM}$. The total length of the analysed genome was $2618 \mathrm{cM}$. ANIMAP [12] or CRIMAP [13] were used to construct the linkage maps. The methods for DNA extraction, PCR reaction protocols, and electrophoresis have been described in previous studies [10,47].

\subsection{Statistical analysis}

QTL analyses consisted of the following steps: (1) a genome scan was carried out using multiple linear regression for four fertility related traits; (2) the significant QTL detected from (1) and milk production QTL detected by Viitala et al. [46] that overlapped with the fertility QTL were reanalysed with the variance component method using a single-trait model (STVC); (3) multitrait pleiotropic $\left(\mathrm{MT}_{\mathrm{P}}\right)$ and linked $\left(\mathrm{MT}_{\mathrm{L}}\right)$ QTL models were analysed when QTL for two fertility traits or one fertility trait and one milk yield trait [46] were detected on the same chromosome.

\subsubsection{Regression method}

Associations between markers and traits were analysed using a multiple marker regression approach [22]. The model used was the following: $y_{i j}=a_{i}+$ $b_{i} x_{i j}+e_{i j}$, where $y_{i j}$ is the breeding value of bull $j$, who belongs to family $i$, $a_{i}$ is the polygenic effect for half-sib family $i, b_{i}$ is the allele substitution effect for a QTL within family $\mathrm{i}, \mathrm{x}_{\mathrm{ij}}$ is the conditional probability for bull $\mathrm{j}$ 
of inheriting the first haplotype from sire $\mathrm{i}$, and $\mathrm{e}_{\mathrm{ij}}$ is the residual. Significance thresholds and $P$-values for the F-statistic, were obtained by permutation, which was repeated 10000 times for each trait and chromosome separately [8]. Genome wise $P$-values were obtained by Bonferroni correction $\mathrm{P}_{\text {genome }}=1-\left(1-\mathrm{P}_{\text {chromosome }}\right)^{29}$, where 29 is the total number of chromosomes analysed.

A two-QTL model was fitted in the regression analysis for those chromosomes that had more than three informative markers if one significant QTL had been detected and if the estimated QTL positions in the individual families indicated two different positions $[44,45]$. With the two-QTL model, the permutations were done to test two QTL vs. no QTL. If this result exceeded the chromosome-wise significance threshold of $5 \%$, the $P$-value for two QTL $v s$. one QTL was obtained from a standard F table. The degrees of freedom for the F statistic were the number of grandsires as the numerator and total number of offspring minus three times the number of grandsires as the denominator.

\subsubsection{Variance component method}

Single- and multi-trait QTL mapping based on the variance component method was carried out using the method described by Lund et al. [27]. The traits were modelled using the following linear mixed model with $\mathrm{n}_{\mathrm{q}}$ number of QTL:

$$
\mathbf{y}=\boldsymbol{\mu}+\mathbf{Z u}+\sum_{\mathrm{i}=\mathbf{1}}^{\mathbf{n}_{\mathrm{q}}} \mathbf{W} \mathbf{q}_{\mathrm{i}}+\mathbf{e},
$$

where $\mathbf{y}$ is a vector of breeding values or DYD recorded on $\mathrm{t}$ traits for each genotyped son, $\boldsymbol{\mu}$ is a vector of overall trait means, $\mathbf{Z}$ and $\mathbf{W}$ are incidence matrices, $\mathbf{u}$ is a vector of random additive polygenic effect results from a combined effect of background genes, $\mathbf{q}_{i}$ is a vector of the effects of the $i^{\text {th }}$ QTL, and $\mathbf{e}$ is a vector of random residual effects. The random variables $\mathbf{u}, \mathbf{q}_{\mathrm{i}}$ and $\mathbf{e}$ are assumed to be multivariate normally distributed and mutually uncorrelated. For details of the method see Lund et al. [27].

The variance components were estimated using the average information restricted maximum likelihood algorithm [18] implemented in the software package DMU [29]. The restricted likelihood was maximised with respect to the variance components associated with the random effects in the model. Maximising a sequence of restricted likelihoods over a grid of specific positions yields a profile of the restricted likelihood for the QTL position. The interval for QTL was estimated by one-LOD support [28]. 


\subsubsection{IBD matrices}

The elements in the IBD matrix are a function of the marker data and the position (p) of a putative QTL on the chromosome. Here we used the most likely marker linkage phase in the sire and computed the IBD matrix using a recursive algorithm [48]. The IBD matrices were computed for every $4 \mathrm{cM}$ along the chromosomes and used in the subsequent variance component estimation procedure.

\subsubsection{Test statistics}

Hypothesis tests for the presence of QTL were based on the asymptotic distribution of the likelihood ratio test $(\mathrm{LRT})$ statistic, $\mathrm{LRT}=-2 \ln \left(\mathrm{L}_{\text {reduced }}-\mathrm{L}_{\text {full }}\right)$, where $\mathrm{L}_{\text {reduced }}$ and $\mathrm{L}_{\text {full }}$ were the maximised likelihoods under the reduced model and full model, respectively. The reduced model always excluded the QTL effect for the chromosome being analysed. The two-QTL models were compared with one-QTL (null) models. Thresholds were calculated using the method presented by Piepho [32].

\subsubsection{Model selection between pleiotropic and linked-QTL models}

Since the pleiotropic and the linked-QTL models are not nested, the Bayesian Information Criterion (BIC) [20,41] was used to evaluate which model was favoured. The two models in the present study entail the same number of parameters and consequently the BIC simplifies to $2 \log \left[\frac{p\left(y \mid \hat{\theta}_{\text {linkage }} M_{\text {linkage }}\right)}{p\left(y \mid \hat{\theta}_{\text {pleiotropy }} M_{\text {pleiotropy }}\right)}\right]$. If the two models are assumed equally likely a priori, the results using this criteria are an approximation to the posterior probability of the pleiotropic model relative to the posterior probability of the linked QTL model (Bayes factor). We used the BIC calibration table by Raftery [35] for interpreting BIC estimates. A BIC score of $\geqslant 6$ (model M1 vs. M2) indicated strong evidence for M1 over M2. Another less formal criterion used to indicate which model is more likely, is the estimated correlation between QTL effects on the two traits $\left(\mathrm{r}_{\mathrm{Q} 12}\right)$ from the pleiotropic model. The rationale behind using $\mathrm{r}_{\mathrm{Q} 12}$ is that if the two traits are under the influence of a biallelic pleiotropic QTL the true value of $\mathrm{r}_{\mathrm{Q} 12}$ will be one. 


\section{RESULTS}

\subsection{Days open}

In the single-trait regression analysis, QTL for DO were detected on BTA1, $2,5,12,20,25$, and 29 at chromosome-wise 5\% significance (Tab. I). The single-trait model with variance component analysis (STVC) confirms QTL on BTA1 and 12 in the same region of the chromosomes (Tab. I). The twoQTL model with regression was fitted for BTA1 and 2. No support was found for this model for either chromosome. In the analysis within families there were two to five families with chromosome-wise significant F-values per chromosome. The positions of the highest F-values on the chromosomes were not consistent between families. The estimated allele substitution effects in these families ranged from 0.7 to 1.5 standard deviations of EBV, which means 5.2 to 11.1 days.

\subsection{Fertility treatments}

With the regression analysis, QTL were detected on BTA1, 10, 15, 19, and 25 at chromosome-wise 5\% significance and on BTA5 and 14 at chromosomewise $1 \%$ significance (Tab. I). The STVC analysis confirms the QTL for FT on BTA1. The two-QTL model using regression analysis was significant for BTA1, 5, and 14 (Tab. II). The strongest evidence for two QTL was on BTA14. There were one to four families with chromosome-wise significant F-values in the analysis within families. The positions of the highest F-values differed between families. The allele substitution effects ranged from 0.6 to 2.2 standard deviations of EBV or $0.62 \%$ to $2.22 \%$ of treatments.

On BTA1 and BTA25 the QTL positions in the across families analysis for DO and FT were overlapping. For both chromosomes the QTL positions were at the end of the chromosome, on BTA1 close to marker BMS4014 and on BTA25 close to marker AF5 (Figs. 1 and 2).

\subsection{Calf mortality}

In the single trait regression analysis, QTL for CM were detected on BTA4, $6,11,15,18$, and 23 at $5 \%$ chromosome-wise significance (Tab. I). The STVC analyses did not confirm any of the QTL for CM, however, the QTL on BTA4 and 15 were close to significance. The two-QTL model using regression was not supported for any of the chromosomes. In the analysis within families 


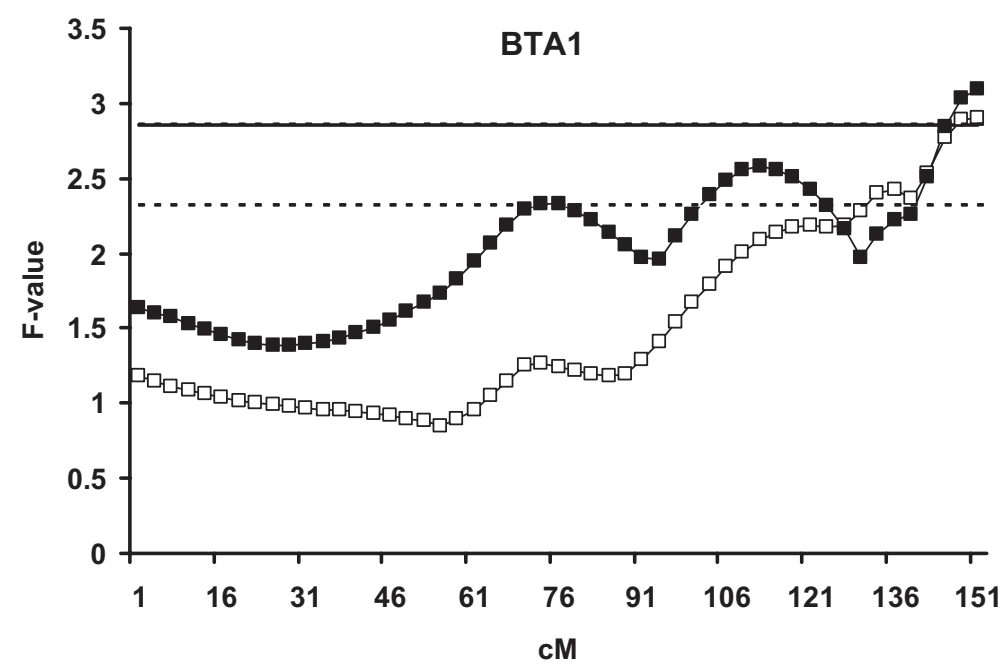

Figure 1. Profiles of linear regression test statistics for BTA1 from single trait analysis across families. Quantitative trait loci were detected for days open $\square$ and fertility treatments $\mathbf{m}$. The upper horizontal line indicates the chromosome-wise 5\% threshold level for fertility treatments and the lower dashed line the chromosome-wise 5\% threshold level for days open.

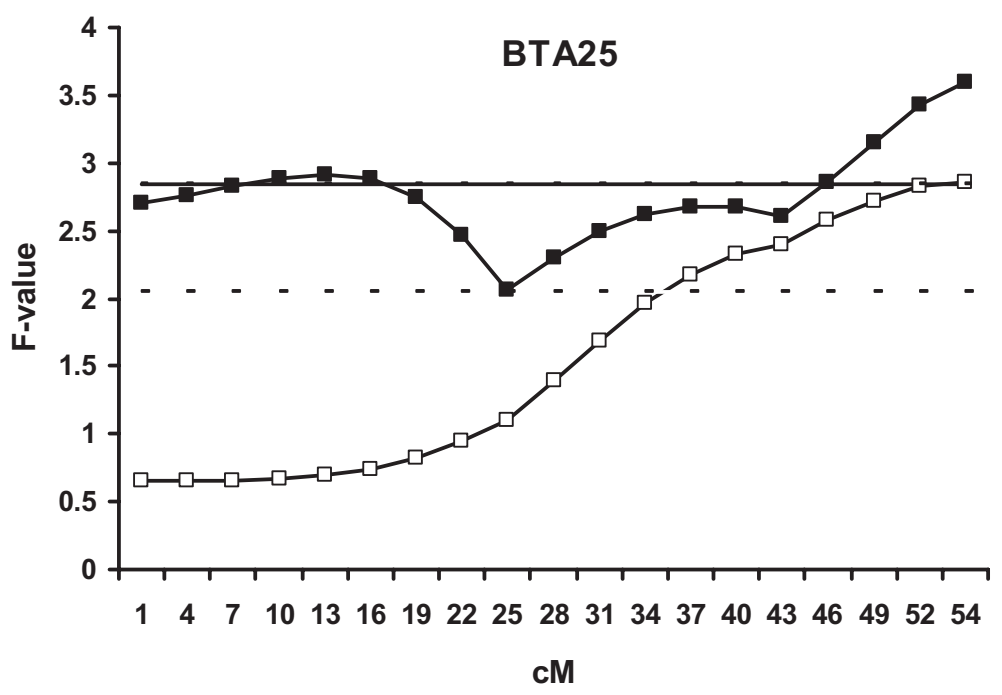

Figure 2. Profiles of linear regression test statistics for BTA25 from single trait analysis across families. Quantitative trait loci were detected for days open $\square$ and fertility treatments $\mathbf{m}$. The $5 \%$ threshold levels for the traits are shown. The upper horizontal line indicates the chromosome-wise $5 \%$ threshold level for fertility treatments and the lower dashed line the chromosome-wise $5 \%$ threshold level for days open. 
Table I. Quantitative trait loci for days open, fertility treatments, calf mortality and non-return rate with regression and variance component methods in Finnish Ayrshire cattle.

\begin{tabular}{|c|c|c|c|c|c|}
\hline \multirow[t]{2}{*}{ Trait } & \multirow[t]{2}{*}{ BTA $^{1}$} & \multicolumn{2}{|c|}{ Regression method } & \multicolumn{2}{|c|}{ Variance component method } \\
\hline & & Pos. $^{2}(\mathrm{cM})$ & F-value & Pos. (cM) & LRT $^{3}$ \\
\hline \multirow[t]{7}{*}{ Days open } & 1 & 146 & $2.75^{* *}$ & 144 & $11.29^{* *}$ \\
\hline & 2 & 2 & $2.86^{* *}$ & 0.1 & 3.26 \\
\hline & 5 & 108 & $2.86^{* *}$ & 107 & 4.29 \\
\hline & 12 & 47 & $2.34^{*}$ & 48 & $8.49^{*}$ \\
\hline & 20 & 1 & $2.44^{*}$ & 2 & 5.80 \\
\hline & 25 & 47 & $2.93^{* *}$ & 45 & 5.19 \\
\hline & 29 & 4 & $2.27^{*}$ & 45 & 4.90 \\
\hline \multirow{7}{*}{$\begin{array}{l}\text { Fertility } \\
\text { treatments }\end{array}$} & 1 & 151 & $3.09^{*}$ & 148 & $9.75^{*}$ \\
\hline & 5 & 113 & $3.94^{* *}$ & 84 & 3.83 \\
\hline & 10 & 145 & $2.99^{*}$ & 2 & 5.83 \\
\hline & 14 & 67 & $3.46^{* *}$ & 50 & 1.37 \\
\hline & 15 & 1 & $3.30^{*}$ & 120 & 4.09 \\
\hline & 19 & 1 & $3.19^{*}$ & 1 & 1.78 \\
\hline & 25 & 54 & $3.60^{* *}$ & - & $<1.0$ \\
\hline \multirow{6}{*}{$\begin{array}{l}\text { Calf } \\
\text { mortality }\end{array}$} & 4 & 17 & $2.36^{*}$ & 1 & 6.60 \\
\hline & 6 & 93 & $2.71^{*}$ & 85 & 3.9 \\
\hline & 11 & 29 & $2.09^{*}$ & 16 & 2.75 \\
\hline & 15 & 115 & $2.08^{*}$ & 120 & 6.33 \\
\hline & 18 & 1 & $2.24^{*}$ & - & $<1.0$ \\
\hline & 23 & 3 & $2.02^{*}$ & 1 & 2.05 \\
\hline \multirow{2}{*}{$\begin{array}{l}\text { Non-return } \\
\text { rate }\end{array}$} & 10 & 68 & $2.06^{*}$ & 144 & 3.54 \\
\hline & 14 & 29 & $2.14^{*}$ & 30 & 2.85 \\
\hline
\end{tabular}

${ }^{1} \mathrm{BTA}=$ Bos taurus chromosome.

${ }^{2}$ Pos. $=$ position.

${ }^{3} \mathrm{LRT}=$ likelihood ratio test statistics.

${ }^{*} P<0.05 ;{ }^{* *} P<0.01$.

there were two to four families with chromosome-wise significant F-values per chromosome. For BTA15, three families had their highest F-values close to marker $M G T G 13 B$. For BTA18, two families had their highest F-values at BMS1355 and two between markers BMS1355 and BMS2213. On the other chromosomes with significant QTL in the across families analysis, the positions of the highest F-values were not consistent between families. The allele substitution effects of the detected QTL ranged from 0.5 to 2.2 standard deviations of $\mathrm{EBV}$, which is $0.45 \%$ to $2.0 \%$ of $\mathrm{CM}$. 
Table II. Results from the two-QTL model for fertility treatments by linear regression.

\begin{tabular}{|c|c|c|c|c|c|c|c|c|c|}
\hline \multirow[b]{2}{*}{ BTA $^{1}$} & \multicolumn{2}{|c|}{$1 v s$. no QTL } & \multicolumn{4}{|c|}{$2 v s$. no QTL } & \multicolumn{3}{|c|}{$2 v s .1 \mathrm{QTL}$} \\
\hline & $\overline{\mathrm{F}^{2}}$ & Pos. $^{3}$ & $5 \% 4$ & $\bar{F}$ & & & $5 \%$ & $\bar{F}$ & $5 \%$ \\
\hline 1 & 3.09 & 151 & 2.85 & 2.71 & 71 & 15 & 2.55 & 2.55 & 1.85 \\
\hline 5 & 3.94 & 113 & 2.8 & 3.3 & 2 & 96 & 2. & 2.57 & 1.85 \\
\hline 14 & 3.46 & 67 & 2.70 & 3.74 & 46 & 76 & 2.29 & 3.76 & 1.85 \\
\hline
\end{tabular}

${ }^{1}$ Bos taurus chromosome.

${ }^{2} \mathrm{~F}$-value.

${ }^{3} \mathrm{QTL}$ position $\mathrm{cM}$.

${ }^{4}$ Threshold level for 5\% significance.

\subsection{Non-return rate}

Non-return rate QTL were found on BTA10 and 14 at 5\% chromosomewise significance (Tab. I). Neither of these QTL was detected by STVC analysis. The allele substitution effects of the detected QTL ranged from 0.7 to 1.6 standard deviations of EBV. This is $2.70 \%$ to $6.16 \%$ of NRR. There was no indication of two separate QTL positions on any of the chromosomes, and the two-QTL model using regression was not applied. In the analysis within families, one to two families had 5\% chromosome-wise significant F-values per chromosome and the positions of the highest F-values were not consistent between families.

\subsection{Single-trait analysis of milk production traits}

Out of the 16 chromosomes observed segregating for fertility related QTL in this study, BTA1, 2, 5, 12, 14 and 25 were analysed by STVC for milk production traits. This was done because QTL for milk production were reported on these chromosomes by Viitala et al. [46] in the same families. The STVC analyses detected QTL for MY on BTA1; for MY and PY on BTA5; MY, PY, and FY on BTA12; FY on BTA14 (Tab. III). None of the QTL for the production traits on BTA2 and 25 were confirmed by STVC analyses.

\subsection{Multi-trait analysis}

Multi-trait analyses were carried out on BTA1, 2, 5, 10, 12, 14, 15, and 25 using the variance component method (Tab. IV). On these chromosomes, fertility QTL were detected in the single trait regression analysis close to milk 
Table III. QTL identified by single-trait analysis using the variance component method on Bos taurus autosomes (BTA) 1, 2, 5, 12, 14 and 25, which shows at least one fertility trait QTL and one QTL for milk production traits in Finnish Ayrshire cattle.

\begin{tabular}{|c|c|c|c|c|c|c|c|c|c|c|c|c|}
\hline & \multicolumn{2}{|c|}{ BTA1 } & \multicolumn{2}{|c|}{ BTA2 } & \multicolumn{2}{|c|}{ BTA5 } & \multicolumn{2}{|c|}{ BTA12 } & \multicolumn{2}{|c|}{ BTA14 } & \multicolumn{2}{|c|}{ BTA25 } \\
\hline Trait & $\begin{array}{l}\text { Pos. } \\
\text { (cM) }\end{array}$ & LRT & $\begin{array}{l}\text { Pos. } \\
\text { (cM) }\end{array}$ & $\begin{array}{l}\text { LRT } \\
\end{array}$ & $\begin{array}{l}\text { Pos. } \\
\text { (cM) }\end{array}$ & LRT & $\begin{array}{l}\text { Pos. } \\
\text { (cM) }\end{array}$ & LRT & $\begin{array}{l}\text { Pos. } \\
\text { (cM) }\end{array}$ & LRT & $\begin{array}{l}\text { Pos. } \\
\text { (cM) }\end{array}$ & $\begin{array}{l}\text { LRT } \\
\end{array}$ \\
\hline MY & 104 & $8.36^{*}$ & 116 & 2.61 & 68 & 8.6 & 28 & $8.45^{*}$ & 0.01 & & 6 & 2.8 \\
\hline PY & 108 & 4.19 & 120 & 5. & 68 & $8.79^{*}$ & 40 & $6.89^{*}$ & - & $<1.0$ & 57 & 4.79 \\
\hline FY & - & $<1.0$ & 112 & 4.78 & - & $<1.0$ & 36 & $15.74^{* *}$ & 0.01 & $11.12^{*}$ & - & $<1.0$ \\
\hline
\end{tabular}

${ }^{*} P<0.05 ;{ }^{* *} P<0.01$.

Table IV. Multi-trait analysis with pleiotropic and linked QTL models on BTA1, 5, 12, 14 and 15 where QTL for both reproduction and milk production were identified in single-trait analysis.

\begin{tabular}{ccccccccc}
\hline BTA & Traits & \multicolumn{3}{c}{ Pleiotropic QTL } & \multicolumn{2}{c}{ 2 Linked QTL } & Comparison \\
& & $\begin{array}{c}\text { Pos. }^{2} \\
(\mathrm{cM})\end{array}$ & LRT $^{4}$ & $\mathrm{r}_{\mathrm{Q}}^{5}$ & $\begin{array}{c}\text { Pos1 }^{3} \\
(\mathrm{cM})\end{array}$ & $\begin{array}{c}\text { Pos2 }^{3} \\
(\mathrm{cM})\end{array}$ & LRT & $\begin{array}{c}\text { BIC } \\
\text { (pleiotropy } \\
\text { vs. linkage) }\end{array}$ \\
\hline BTA1 & DO and FT & 148 & $17.8^{* * 7}$ & 0.96 & 148 & 80 & 9.48 & 8.4 \\
& DO and MY & 144 & 8.1 & -0.28 & 144 & 104 & $17.1^{* *}$ & -9.0 \\
& FT and MY & 144 & 12.1 & -0.95 & 156 & 104 & 11.9 & 0.2 \\
BTA5 & FT and MY & 72 & 11.5 & -0.24 & 0.1 & 72 & $14.1^{*}$ & -2.6 \\
& FT and PY & 68 & 11.2 & -0.47 & 0 & 68 & $13.9^{*}$ & -2.7 \\
BTA12 & DO and FY & 31 & $13.9^{*}$ & -0.75 & 52 & 31 & $14.6^{*}$ & -0.7 \\
& & & & & & & & \\
BTA14 & FT and NRR & 36 & 4.4 & 0.99 & 48 & 32 & 4.2 & 0.2 \\
& FT and FY & 0.1 & 11.2 & -0.99 & 52 & 0.1 & $12.1^{*}$ & -0.9 \\
& NRR and FY & 4 & $12.8^{*}$ & -0.45 & 32 & 0.1 & $13.8^{*}$ & 1.0 \\
& & & & & & & & \\
BTA15 & FT and CM & 120 & $13.4^{*}$ & 0.35 & 8 & 120 & 12.1 & 1.3 \\
\hline
\end{tabular}

${ }^{1} \mathrm{DO}=$ days open; FT $=$ fertility treatments; $\mathrm{MY}=$ milk yield; $\mathrm{PY}=$ protein yield $\mathrm{FY}=$ fat yield $; \mathrm{NRR}=$ non-return rate; $\mathrm{CM}=$ calf mortality.

${ }^{2}$ Pos. $=$ position.

${ }^{3}$ Pos 1 and Pos 2 = position of the QTL affecting the first and second trait respectively.

${ }^{4} \mathrm{LRT}=$ likelihood ratio test statistics.

${ }^{5} \mathrm{r}_{\mathrm{Q}}=$ correlation between the QTL effects.

${ }^{6} \mathrm{BIC}=$ Bayesian information criterion.

${ }^{7 *} P \leqslant 0.05 ;{ }^{* *} P \leqslant 0.01$. 
QTL [46] detected earlier and some of them had QTL regions affecting two different fertility traits. The analysed traits were DO, FT, CM, NRR, MY, PY, and FY. Out of the eight chromosomes analysed with multi-trait models, there was no indication of pleiotropic or linked QTL affecting fertility and milk, segregating on BTA2, BTA10 or BTA25.

BTA1. With the STVC analysis, a QTL for DO was detected at $1 \%$ chromosome-wise significance with the peak position at $144 \mathrm{cM}$ and QTL for FT and MY at 5\% significance with peak positions at $148 \mathrm{cM}$ and $104 \mathrm{cM}$. The $\mathrm{MT}_{\mathrm{P}}$ model for DO and FT was significant $(P<0.01)$ and the peak QTL position was at $148 \mathrm{cM}$. The LRT for the $\mathrm{MT}_{\mathrm{L}}$ model was not significant. The BIC (8.4) was strongly in favour of the $\mathrm{MT}_{\mathrm{P}}$ model over the $\mathrm{MT}_{\mathrm{L}}$ model. Besides, the correlation between the QTL effects $\left(\mathrm{r}_{\mathrm{Q}}\right)$ was also high (0.96). One pleiotropic QTL around $148 \mathrm{cM}$ is affecting both DO and FT. The $\mathrm{MT}_{\mathrm{P}}$ model was not significant for $\mathrm{DO}$ and $\mathrm{MY}$, while the $\mathrm{MT}_{\mathrm{L}}$ model for these two traits was significant $(P<0.01)$. The BIC in favour of $\mathrm{MT}_{\mathrm{L}}$ over $\mathrm{MT}_{\mathrm{P}}$ was 9.0, which strongly favours the linked model. Additionally, the $\mathrm{r}_{\mathrm{Q}}$ was low $(-0.28)$, which also supports this. The BIC and $\mathrm{r}_{\mathrm{Q}}$ indicate that there may be two linked QTL on BTA1, one near $144 \mathrm{cM}$ affecting DO and FT, and one near $104 \mathrm{cM}$ affecting MY. For FT and MY, both the $\mathrm{MT}_{\mathrm{P}}$ and $\mathrm{MT}_{\mathrm{L}}$ model were approaching 5\% significance. The BIC (0.2) estimate for $\mathrm{MT}_{\mathrm{P}}$ over $\mathrm{MT}_{\mathrm{L}}$ indicates that both models are equally likely. In the single-trait regression analysis, there was an indication of two QTL on BTA1 affecting FT. However, the linked QTL model affecting FT (with putative positions at $72 \mathrm{cM}$ and $148 \mathrm{cM}, \mathrm{LRT}=12.1$ ) was not significant compared with the one-QTL model in the variance component method. When a multi-trait linked QTL model, with a pleiotropic QTL at $104 \mathrm{cM}$ affecting both FT and MY, and the other QTL at $148 \mathrm{cM}$ affecting only FT was fitted, the LRT did not exceed the significance threshold. Overall the results indicate that two linked QTL are segregating on BTA1, one QTL (at $148 \mathrm{cM}$ ) affecting DO and FT and the other (at $104 \mathrm{cM}$ ) affecting MY.

BTA5. With the STVC analysis, QTL for MY and PY were found at 5\% chromosome-wise significance with peak LRT at $68 \mathrm{cM}$ (Tab. III). Although, the STVC model for FT on BTA5 did not reach the 5\% significance level, the QTL profile peak around 84-88 cM overlaps with the QTL profiles for MY and PY. Therefore, multi-trait analyses of FT and milk traits were carried out. The MTP models, one with FT and MY, and the other with FT and PY were not significant, but the $\mathrm{MT}_{\mathrm{L}}$ models were significant at 5\% (Tab. IV). The BIC estimate was in favour of the linked QTL model but did not provide conclusive evidence for any one model over the other. 


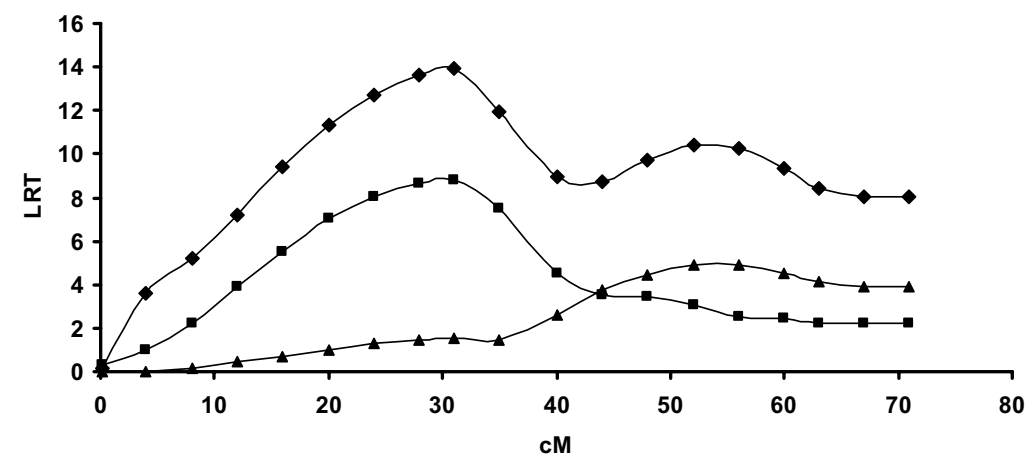

Figure 3. QTL profile on BTA12 from multi-trait variance component analysis of days open and fat yield. The QTL affecting both days open and fat yield $\downarrow$; only fat yield $\mathbf{a}$; and only days open $\boldsymbol{\Lambda}$.

BTA12. The QTL in the STVC analysis were chromosome-wise significant at $1 \%$ for FY and at $5 \%$ for DO, MY, and PY (Tabs. IV and III). The STVC for FT was not significant. A $\mathrm{MT}_{\mathrm{P}}$ model for the three yield traits supports a pleiotropic QTL at $31 \mathrm{cM}$. The $\mathrm{MT}_{\mathrm{P}}$ model for DO and FT was not significant. It seems that the QTL is affecting DO but not FT. The $\mathrm{MT}_{\mathrm{P}}$ and the $\mathrm{MT}_{\mathrm{L}}$ models for DO and FY were significant $(P<0.05)$ (Tab. IV). The BIC comparison of the models was inconclusive. Therefore, it was not possible to select one model over the other. In the STVC analyses, the highest LRT for DO was at $56 \mathrm{cM}$ (close to $M B 100$ at $53.9 \mathrm{cM}$ ), while the highest LRT for FY was at $31 \mathrm{cM}$ (closer to BM6404 at $31.7 \mathrm{cM}$ ). There may be two linked QTL segregating on BTA12. The linked QTL model was also supported when a QTL was fitted to affect either DO or FY in a multi-trait model (Fig. 3). When the QTL was fitted to affect only FY in a multi-trait model with DO and FY the highest LRT was at $31 \mathrm{cM}$. When in a similar multi-trait model the QTL was fitted to affect only DO it did not exceed the significance threshold.

BTA14. The QTL at $67 \mathrm{cM}$ on BTA14 affecting FT was significant at $1 \%$ and the NRR QTL at $29 \mathrm{cM}$ was significant at $5 \%$ in single-trait regression analysis. In the STVC analyses, the QTL for FY was significant and located in the proximal region of BTA14. This may be the DGAT1 gene, which has a major effect on milk composition and particularly fat content $[14,49]$. The $\mathrm{MT}_{\mathrm{P}}$ model for FT and FY approached 5\% significance, while the $\mathrm{MT}_{\mathrm{L}}$ model was significant (5\%) (Tab. IV). Both the $\mathrm{MT}_{\mathrm{P}}$ and $\mathrm{MT}_{\mathrm{L}}$ models for $\mathrm{FY}$ and NRR were significant $(P<0.05)$. The BIC estimate did not favour any of the competing models. In STVC analysis, the fat yield QTL was located at the proximal end of BTA14 $(0.1 \mathrm{cM})$ and the QTL for FT and NRR were at 67 and $29 \mathrm{cM}$, respectively. These results indicate that the QTL located 
at the centromeric region of BTA14 is affecting fat yield. None of the $\mathrm{MT}_{\mathrm{P}}$ and $\mathrm{MT}_{\mathrm{L}}$ models for FT and NRR were significant on BTA14.

BTA15. The results from the STVC analysis indicated that two QTL may be segregating for FT on BTA15, at 12 and $120 \mathrm{cM}$. The CM QTL approached $5 \%$ significance and located at $115 \mathrm{cM}$. The $\mathrm{MT}_{\mathrm{P}}$ model for FT and $\mathrm{CM}$ was significant $(P<0.05)$ and the peak LRT was at $120 \mathrm{cM}$. The same model also indicated another pleiotropic QTL approaching significance at $16 \mathrm{cM}$. When the QTL was fitted to affect FT in a multi-trait model, the QTL profile exceeded the $5 \%$ significance level at $120 \mathrm{cM}$ and was close to the $5 \%$ significant level at $16 \mathrm{cM}$. While when a QTL was fitted to affect only CM in a multi-trait model, no evidence of the QTL at $16 \mathrm{cM}$ was observed and the QTL at $120 \mathrm{cM}$ approached the 5\% significance threshold. It seems that the QTL segregating at the distal end of the chromosome is affecting both FT and CM and the QTL at the proximal region is only affecting FT.

\subsection{Increased power in multi-trait models}

The multi-trait analyses using the variance component method identified more QTL compared with single-trait variance component analyses. For example, on BTA5 the STVC analysis could not confirm any QTL for FT segregating on this chromosome. However, when FT was jointly analysed with MY or PY, both $\mathrm{MT}_{\mathrm{L}}$ models identified one QTL at the centromeric region of BTA5 for FT. Similarly, on BTA14, the STVC analyses did not exceed the significance threshold for FT and NRR. While the $\mathrm{MT}_{\mathrm{L}}$ models with FY identified a QTL for FT at $52 \mathrm{cM}$ and a QTL for NRR at $32 \mathrm{cM}$. A similar phenomenon was also observed on BTA15 for FT and CM. None of the STVC analyses for these two traits was significant on this chromosome. However, the $\mathrm{MT}_{\mathrm{P}}$ model for FT and CM identified a pleiotropic QTL at $120 \mathrm{cM}$.

\section{DISCUSSION}

A genome scan was carried out for four fertility related traits in Finnish Ayrshire cattle using the multiple linear regression method. A variance component method was used for multi-trait analysis with pleiotropic and linked QTL. Since we used VC for multi-trait analysis, we reanalysed the significant QTL models observed with the regression method by single-trait VC. The QTL for three milk production traits identified by Viitala et al. [46] were also reanalysed by the STVC method for the chromosomes where there was at least one fertility related QTL. 
In this QTL mapping study, seven chromosome-wise significant QTL were suggested for DO, seven for FT, six for CM, and two for NRR using the regression method. When these significant QTL were reanalysed by STVC, some of the QTL were not detected. However, when STVC analyses were carried out within those families segregating for the QTL in the regression method, the QTL effects were observed (results not shown). Across family linkage analyses using the variance component method with both segregating and nonsegregating families may have averaged out the QTL effect. The VC method may not detect QTL with a low allele frequency whereas regression detects these effects [9].

FT as a trait have only been analysed in one previous study [15], where possible QTL on BTA1, 3, and 22 were found. A QTL for FT was detected on BTA1 in the present study but at the opposite end of the chromosome. The other two QTL were not supported. Three additional studies have detected QTL for female fertility [2, 6, 39]. Schrooten et al. [39] analysed NRR in the cow and detected QTL on BTA2 and 9. Ashwell et al. [2] defined the trait as pregnancy rate and detected a QTL on BTA18 and putative QTL on BTA6, 14, $16,18,27$, and 28. Boichard et al. [6] defined the trait as success/failure of each insemination of the daughter and found QTL on BTA1 and 7. Of these female fertility QTL only those on BTA1, 2, and 14 are supported by the present study.

In the present study, QTL for DO were suggested on seven chromosomes and two were confirmed by STVC analyses. The trait was calculated as the interval from calving to pregnancy. Schrooten et al. [39] defined DO as the interval from calving to first insemination. They suggested QTL for DO on BTA6 and 17, and none of them were found in the present study.

Calf mortality (stillbirth) as a maternal trait has been previously mapped by Holmberg and Andersson-Eklund [15] and Kühn et al. [24]. QTL were suggested on BTA4 and 19 and detected at genome-wise significance on BTA7 and 11 [15] and BTA8, 10, 18, and X/Y [24]. The QTL on BTA4, 11 and 18 were supported in the present study. The QTL on BTA4 is located near marker HUJ673 in the Swedish and the present studies. In our study, the position of the QTL on BTA18 is at the opposite end of the chromosome close to BMS1355 instead of TGLA227 in the study by Kühn et al. [24]. Additionally, a QTL reported by Kühn et al. [24] for direct stillbirth, which is related to maternal $\mathrm{CM}$, was supported in the present study where a QTL for CM was suggested on BTA6.

In this study, putative chromosome-wise significant QTL were found for paternal NRR on BTA10 and 14. NRR as a paternal effect was previously mapped in one study [24] in which QTL affecting NRR were found on BTA10 and 18. 
The position of the QTL on BTA10 [24] was between markers TGLA378 and TGLA102, which is close to our finding near the marker ILSTS53.

When comparing the fertility QTL with the positions of the milk trait QTL detected in an earlier study in the same families [46], several milk and fertility QTL were found on the same chromosomes. For example, on BTA25, where QTL were detected for DO and FT at the end of the chromosome, QTL for milk yield and protein yield were also detected. Furthermore, BTA1, 2, 5, and 12 harbour QTL for milk and fertility on approximately the same chromosome segments according to the regression based linkage analysis.

Multi-trait QTL analyses were carried out on eight chromosomes, which harbour QTL for more than one fertility trait or at least one fertility related trait and one milk production trait identified earlier by Viitala et al. [46] in the same population. We selected the chromosomes based on the significance of the QTL in the regression analysis. Though some of these QTL were not significant in the single-trait $\mathrm{VC}$ method, we did not put this as a precondition for selecting the chromosome and trait combinations. This was done as a multitrait analysis for a pleiotropic QTL because it has higher statistical power of detection and a higher precision of the estimated map position compared to analysing the traits individually [19,21,43]. Sørensen et al. [43] observed that this is especially true when a second correlated trait with higher heritability (e.g. milk yield traits in our study) is used together with a low heritability trait (e.g. fertility traits in our study). Besides, a majority of the QTL identified by regression, which did not exceed the significance threshold in STVC analysis, had suggestive evidence of QTL segregation in the same region of the chromosome when analysed with STVC. Therefore, we kept a liberal entry level for the QTL to be included in the multi-trait analysis. Our results support the earlier findings of Jiang and Zeng [19], Knott and Haley [21] and Sørensen et al. [43] that show that multi-trait analyses have more power in detecting QTL compared to single-trait analyses.

Multi-trait QTL analyses were able to distinguish pleiotropic QTL from linked QTL only on BTA1 and not on the other chromosomes. The results also indicated linked QTL on BTA5, 12, 14 and 15 for fertility related traits and milk production traits, but it was not possible to precisely select the linked model over the pleiotropic model or vice versa. The QTL intervals (one-LOD support) on a single chromosome affecting more than one trait were large and overlapping. Also, the segregating families had QTL peaks spread over a considerably large region of the chromosome. The marker density used in the genome scan was sparse (average marker spacing $19 \mathrm{cM}$ ) and increasing marker density may help in reducing the QTL interval in linkage 
mapping especially to distinguish pleiotropic/linked QTL. The traits show variable amounts of genetic correlation. A significant QTL for a given trait might be non-significant for a highly correlated trait but still have an effect on it [11]. This makes the separation between a QTL having a pleiotropic effect on two traits and a QTL affecting only one trait and showing an effect on the other trait due to a linked QTL, difficult.

\section{CONCLUSIONS}

Four traits related to bovine fertility were analysed in a QTL mapping study. A total of 22 chromosome-wise significant QTL were suggested in regression analysis and three were confirmed with the single trait variance component method. Only few of the detected QTL have been reported in earlier studies and many of the QTL of the previous studies were not supported in the present study. This could be due to a low power of detection related to the low heritability and difficulty to adequately measure these traits. Some of the fertility trait QTL are closely linked to milk production QTL or the QTL show pleiotropic effects on milk production and fertility traits. A denser marker map, larger population and linkage disequilibrium based mapping may be needed to distinguish two-linked QTL from a pleiotropic QTL.

\section{ACKNOWLEDGEMENTS}

We would like to thank Anneli Virta, Jonna Roito and Tiina Jaakkola for the laboratory work, Jukka Pösö from the Finnish Animal Breeding Association for providing the EBV of the bulls, and the AI stations for semen samples. The research was partly funded by the Ministry of Agriculture and Forestry of Finland (Research grant 4750/501/2004) and the Finnish Animal Breeding Association.

\section{REFERENCES}

[1] Akaike H., A new look at the statistical model identification, IEEE Trans. Automat. Cont. 19 (1974) 716-723.

[2] Ashwell M.S., Heyen D.W., Sonstegard T.S., van Tassell C.P., Da Y., VanRaden P.M., Ron M., Weller J.I., Lewin H.A., Detection of quantitative trait loci affecting milk production, health, and reproductive traits in Holstein cattle, J. Dairy Sci. 87 (2004) 468-475. 
[3] Ball R., Bayesian methods for quantitative trait loci mapping based on model selection: approximate analysis using the Bayesian information criterion, Genetics 159 (2001) 1351-1364.

[4] Blattman A.N., Kirkpatrick B.W., Gregory K.E., A search for quantitative trait loci for ovulation rate in cattle, Anim. Genet. 27 (1996) 157-162.

[5] Bogdan M., Ghosh J.K., Doerge R.W., Modifying the Schwarz Bayesian information criterion to locate multiple interacting quantitative trait loci, Genetics 167 (2004) 989-999.

[6] Boichard D., Grohs C., Bourgeois F., Cerqueira F., Faugeras R., Neau A., Rupp R., Amigues Y., Boscher M.Y., Leveziel H., Detection of genes influencing economic traits in three French dairy cattle breeds, Genet. Sel. Evol. 35 (2003) 77-101.

[7] Broman K.W., Speed T.P., A model selection approach for the identification of quantitative trait loci in experimental crosses, J. R. Stat. Soc. B 64 (2002) 641-656.

[8] Churchill G.A., Doerge R.W., Empirical threshold values for quantitative trait mapping, Genetics 138 (1994) 963-971.

[9] de Koning D.J., Pong-Wong R., Varona L., Evans G.J., Giuffra E., Sanchez A., Plastow G., Noguera J.L., Andersson L., Haley C.S., Full pedigree quantitative trait locus analysis in commercial pigs using variance components, J. Anim. Sci. 81 (2003) 2155-2163.

[10] Elo K., Vilkki J., de Koning D.J., Velmala R.J., Mäki-Tanila A.V., A quantitative trait locus for live weight maps to bovine chromosome 23, Mamm. Genome 10 (1999) 831-835.

[11] Gautier M., Barcelona R.R., Fritz S., Grohs C., Druet T., Boichard D., Eggen A., Meuwissen T.H.E., Fine mapping and physical characterization of two linked quantitative trait loci affecting milk fat yield in dairy cattle on BTA26, Genetics 172 (2006) 425-436.

[12] Georges M., Nielsen D., Mackinnon M., Mishra A., Okimoto R., Pasquino A.T., Sargeant L.S., Sorensen A., Steele M.R., Zhao X., Mapping quantitative trait loci controlling milk production in dairy cattle exploiting progeny testing, Genetics 139 (1995) 907-920.

[13] Green P., Falls K., Crooks S., Documentation of CRIMAP, version 2.4, Washington University School of Medicine, St. Louis, MO, 1990.

[14] Grisart B., Coppieters W., Farnir F., Karim L., Ford C., Berzi P., Cambisano N., Mni M., Reid S., Simon P., Spelman R., Georges M., Snell R., Positional candidate cloning of a QTL in dairy cattle: Identification of a missense mutation in the bovine DGAT1 gene with major effect on milk yield and composition, Genome Res. 12 (2002) 222-231.

[15] Holmberg M., Andersson-Eklund L., Quantitative trait loci affecting fertility and calving traits in Swedish dairy cattle, J. Dairy Sci. 89 (2006) 3664-3671.

[16] Jansen R.C., Interval mapping of multiple quantitative trait loci, Genetics 135 (1993) 205-211.

[17] Jansen R.C., Stam P., High resolution of quantitative traits into multiple loci via interval mapping, Genetics 136 (1994) 1447-1455. 
[18] Jensen J., Mantysaari E., Madsen P., Thompson R., Residual maximum likelihood estimation of (co)variance components in multivariate mixed linear models using average information, J. Ind. Soc. Agric. Stat. 49 (1997) 215-236.

[19] Jiang C., Zeng Z.B., Multiple trait analysis of genetic mapping for quantitative trait loci, Genetics 140 (1995) 1111-1127.

[20] Kass R.E., Raftery A.E., Bayes factors, J. Am. Stat. Assoc. 90 (1995) 773-795.

[21] Knott S.A., Haley C.S., Multi trait least squares for quantitative trait loci detection, Genetics 156 (2000) 899-911.

[22] Knott S.A., Elsen J.M., Haley C.S., Methods for multiple-marker mapping of quantitative trait loci in half-sib populations, Theor. Appl. Genet. 93 (1996) 71-80.

[23] Kragelund K., Hillel J., Kalay D., Genetic and phenotypic relationship between reproduction and milk production, J. Dairy Sci. 62 (1979) 468-474.

[24] Kühn C., Bennewitz J., Reinsch N., Xu N., Thomsen H., Looft C., Brockmann G.A., Schwerin M., Weimann C., Hiendleder S., Erhardt G., Medjugorac I., Förster M., Brenig B., Reinhardt F., Reents R., Russ I., Averdunk G., Blümel J., Kalm E., Quantitative trait loci mapping functional traits in the German Holstein cattle population, J. Dairy Sci. 86 (2003) 360-368.

[25] Lande R., Thompson R., Efficiency of marker-assisted selection in the improvement of quantitative traits, Genetics 124 (1990) 743-756.

[26] Lien S., Karlsen A., Klemetsdal G., Våge D.I., Olsaker I., Klungland H., Aasland M., Heringstad B., Ruane J., Gomez-Raya L., A primary screen of the bovine genome for quantitative trait loci affecting twinning rate, Mamm. Genome 11 (2000) 877-882.

[27] Lund M.S., Sørensen P., Guldbrandtsen B., Sorensen D.A., Multitrait fine mapping of quantitative trait loci using combined linkage disequilibria and linkage analysis, Genetics 163 (2003) 405-410.

[28] Lynch M., Walsh J.B., Genetics and analysis of quantitative traits, 1st Edn., Sinauer Associates, Sunderland, 1998.

[29] Madsen P., Sørensen P., Su G., Damgaard L.H., Thomsen H., Labouriau R., DMU - A package for analyzing multivariate mixed models, 8th World Congress on Genetics Applied to Livestock Production, August 2006, Belo Horizonte, MG, Brazil, Book of Abstracts, pp. 247.

[30] Nakamichi R., Ukai Y., Kishino H., Detection of closely linked multiple quantitative trait loci using genetic algorithm, Genetics 158 (2001) 463-475.

[31] Philipsson J., Genetic aspects of female fertility in dairy cattle, Livest. Prod. Sci. 8 (1981) 307-319.

[32] Piepho H.P., A quick method for computing approximate threshold for quantitative trait loci detection, Genetics 157 (2001) 425-432.

[33] Piepho H.P., Gauch Jr. H.G., Marker pair selection for mapping quantitative trait loci, Genetics 157 (2001) 433-444.

[34] Pösö J., Mäntysaari E.A., Genetic relationships between reproductive disorders, operational days open and milk yield, Livest. Prod. Sci. 46 (1996) 41-48.

[35] Raftery A.E., Approximate Bayes factors and accounting for model uncertainty in generalized linear models, Biometrika 83 (1996) 251-266. 
[36] Rautala H., Terveystarkkailun tulokset 2000, Nauta 31 (2001) 22-23.

[37] Royal M.D., Flint A.P.F., Woolliams J.A., Genetic and phenotypic relationships among endocrine and traditional fertility traits and production traits in HolsteinFresian dairy cows, J. Dairy Sci. 85 (2002) 958-967.

[38] Ruane J., Colleau J.J., Marker assisted selection for a sex-limited character in a nucleus breeding population, J. Dairy Sci. 79 (1996) 1666-1678.

[39] Schrooten C., Bovenhuis H., Coppieters W., Arendonk J.A., Whole genome scan to detect quantitative trait loci for conformation and functional traits in dairy cattle, J. Dairy Sci. 8 (2000) 795-806.

[40] Schulman N.F., Viitala S.M., de Koning D.J., Virta J., Mäki-Tanila A., Vilkki J.H, Quantitative trait loci for health traits in Finnish Ayrshire cattle, J. Dairy Sci. 87 (2004) 443-449.

[41] Schwarz G., Estimating the dimension of the model, Ann. Stat. 6 (1978) 461-464.

[42] Siegmund D., Model selection in irregular problems: application and mapping of QTLs, Biometrika 91 (2004) 785-800.

[43] Sørensen P., Lund M.S., Guldbrandtsen B., Jensen J., Sorensen D., A comparison of bivariate and univariate QTL mapping in livestock populations, Genet. Sel. Evol. 35 (2003) 605-622.

[44] Spelman R.J., Coppieters W., Karim L., van Arendonk J.A., Bovenhuis H., Quantitative trait loci analysis for five milk production traits on chromosome six in the Dutch Holstein-Friesian population, Genetics 144 (1996) 1799-1808.

[45] Velmala R.J., Vilkki J.H., Elo K.T., de Koning D.J., Mäki-Tanila A.V., A search for quantitative trait loci for milk production traits on chromosome 6 in Finnish Ayrshire cattle, Anim. Genet. 30 (1999) 136-143.

[46] Viitala S.M., Schulman N.F., de Koning D.J., Elo K., Kinos R., Virta A., Virta J., Mäki-Tanila A., Vilkki J.H., Quantitative trait loci affecting milk production traits in Finnish Ayrshire dairy cattle, J. Dairy Sci. 86 (2003) 1828-1836.

[47] Vilkki J.H., de Koning D.J., Elo K., Velmala R., Mäki-Tanila A., Multiple marker mapping of quantitative trait loci of Finnish dairy cattle by regression, J. Dairy Sci. 80 (1997) 198-204.

[48] Wang T., Fernando R.L., van der Beek S., Grossman M., Covariance between relatives for a marked quantitative trait locus, Genet. Sel. Evol. 27 (1995) 251-274.

[49] Winter A., Kramer W., Werner F.A.O., Kollers S., Kata S., Durstewitz G., Buitkamp J., Womack J.E., Thaller G., Fries R., Association of a lysine232/alanine polymorphism in a bovine gene encoding acyl-coA; diacylglycerol acyltransferase (DGAT1) with variation at a quantitative trait locus for milk fat content, Proc. Natl. Acad. Sci. 99 (2002) 9300-9305. 